\title{
On the Status and Effect of Women in Popular Entertainment Culture
}

\author{
Ting-ting Zhou \\ Art Department of Shandong University (Weihai), Weihai, Shandonng, China
}

\begin{abstract}
Popular entertainment culture accompanies the mature of the market economy and the prosperity of cultural industries. It uses modern media, faces the public and aims to produce and consumes in mass the contemporary culture with extensive aesthetic and extensive entertainment features. In the development process of popular entertainment culture, every different group poses significant impact on the formation, status and development of popular entertainment culture, especially the female group. In some popular entertainment culture activities, women occupy a dominant position, playing a leading role. This phenomenon is closely linked to the development of our country's economic and cultural environment as well as the characteristic of the mass entertainment culture.
\end{abstract}

Keywords-Mass entertainment culture, Female, Status, Effect

\section{论女性群体在大众娱乐文化中的地位和作用}

\author{
周婷婷 \\ 山东大学（威海）艺术学院, 威海, 山东, 中国
}

摘 要 大众娱乐文化是伴随着市场经济的成熟和文化产业的繁荣而产生的, 以全球化的现代传媒为介质的, 面向最大范围的 大众群体的, 有目的地大批量生产和消费的, 具有泛审美和泛娱乐化的特点的当代文化。在大众娱乐文化的发展过程中, 不同群体 对大众娱乐文化的形成、现状和发展都有着极其重要的影响。女性群体对大众娱乐文化发展的作用尤其突出, 在某些大众娱乐文化 活动中，女性占据着主体地位，发挥着主导作用。这与我国经济文化环境的发展以及大众娱乐文化的特性是有着密切联系的。

关键词 大众娱乐文化；女性；地位；作用

20 世纪 90 年代初期, 中国社会在经历了曲折的改革 之后终于确立了自己的目标, 建立了具有中国特色社会主 义市场经济。随着中国特色社会主义市场经济的完善和全 球现代化的发展, 我国物质生产和消费逐步繁荣, 政治民 主环境逐渐自由宽松、消费社会全面启动、大众文化日益 占据主流、科学技术也高速发展。在这些大背景下, 中国 大陆的大众娱乐文化开始蓬勃兴起。可以说, 大众娱乐时 代的到来是社会进步的表现, 是历史发展之大势。

大众娱乐文化究竟如何定义? 又包括哪些方面的内 容? 关于这两个问题, 至今在学界仍莫衷一是, 没有明确 的界定。为了方便下文探讨和分析, 笔者给大众娱乐文化 做了一个界定: 大众娱乐文化是伴随着市场经济的成熟和

文化产业的繁荣而产生的, 以全球化的现代传媒为介
质的, 面向最大范围的大众群体的, 有目的地大批量生产 和消费的, 具有泛审美和泛娱乐化的特点的当代文化。其 包含的活动形式多样, 具有娱乐性、流行性、短暂性、可 消费、低成本、大量生产、有诱惑力等特点。大众娱乐文 化的发展满足了当代人精神需求的多样化、当代人本能需 求的层梯性、有助于释放当代人的现代性焦虑，是一种全 民的文化、趣味性的文化, 是群众喜闻乐见的文化, 也是 动态发展的文化。

大众娱乐文化的活动载体形式包含了悲喜剧、各种比 赛和游戏、音乐舞蹈表演和欣赏等等。按照活动的主要行 为方式, 大众娱乐文化主要包含欣赏类、运动类、消费类 三大类。

欣赏类主要是以大众传媒方式 (如 TV, 网络视频等)

山东省女性人力资源开发与管理研究基地开放基金项目（YB201412） 
为途径供大众 (观众) 观看欣赏的, 如选秀节目、间关节 目、热播肥㿝剧、流行电影、流行歌曲等。选秀节目中较 有代表性的如“超级女声”“快乐男声”“我是歌手”“最强大 脑”“啯好声音”“星光大道”等, 妇孺皆知, 收视率极高, 诸多参赛者或歌曲都会成为人们茶余饭后的谈资。闯关类 节目如“黄金 300 秒”“快乐向前冲”“开门大吉”“英雄闯天 关”“一站到底”等, 也是大众喜闻乐见的娱乐节目。肥㿝剧 则例如《大长今》《宫》《甄嬛传》《我爱我家》等等。流行 电影如 《人在圆途》《泰圆》《小时代》等等, 均成为了引 领当时與论及娱乐圈的当红话题。流行歌曲则以 《志否》 《最炫民族风》《小苹果》等神曲最具代表性。

运动类主要是以群体性活动为主的运动形式, 如广场 舞、街舞、花样篮球、秧歌、戏曲等。其中广场舞最具代 表性。广场舞是最近几年兴起的一种中老年喜爱的流行广 场舞蹈, 更标准的说法是踏歌广场舞。人们随着音乐高低 音节奏而有序踏出舞步, 十分简单易学, 现在广泛流行于 网络和各处广场空地。

消费类主要是以消费带动娱乐的社会性活动, 如双十 一购物狂欢节、大型商场内购会、KTV、蹦迪等节日性、 娱乐性的消费。随着经济的快速发展和娱乐形式的多样化， 人们的娱乐文化也体现出了强烈消费特征。吃饭加唱 KTV 似乎成了全民娱乐的一种模式化方式。而购物狂欢节更是 轰动全国，一日之间全民都处于“秒杀”“低价”的购物乐趣 之中。

虽然我们可以大致地将大众娱乐文化分为这三类, 但 是各个类别并非是界限分明的, 其中也有着紧密联系和部 分交叉。

在大众娱乐文化的发展过程中, 不能忽视有着不同性 别、年龄、地区、知识水平差异的群体。不同群体对大众 娱乐文化的形成、现状和发展都有着极其重要的影响。而 在上述的几个方面中, 性别方面的差异对大众娱乐文化的 发展的影响是最为明显的。在男女两性中, 女性群体对大 众娱乐文化的发展起到十分重要的作用。可以说, 在某些 大众娱乐文化活动中, 女性发挥着主体乃至主导的作用。

为了说明女性群体在大众娱乐文化中的这一地位, 我 们选取了大众娱乐文化三大类别中的具有代表性的 5 个项 目--电视娱乐节目、当红电影、广场舞、节日性购物、KTV, 以威海市为例, 统计并分析了参与群众的性别与年龄等状 况。

在威海市市政府广场、滨海公园、威高广场等发放问 卷 300 份, 回收 281 份, 回收率 93.6\%, 剔除无效问卷 7 份, 有效问卷为 274 份, 有效回收率为 $91.3 \%$ 。其中, 男 性填写 136 份, 女性填写 138 份, 为了便于分析, 我们又 随机剔除了女性填写问卷 2 份。最终分析问卷 272 份。问
卷调查了大众对常见的大众娱乐活动的兴趣与参与频率, 并通过 excel 的统计分析得出以下数据:

表 1 大众娱乐活动的兴趣与参与频率调查表

\begin{tabular}{|c|c|c|c|c|}
\hline 娱乐项目 & 男性人数 & 参与率 (男) & 女性人数 & 参与率 (女) \\
\hline 电视节目 & 103 & $75.7 \%$ & 121 & $88.9 \%$ \\
\hline 电影 & 69 & $50.7 \%$ & 87 & $63.9 \%$ \\
\hline 广场舞 & 33 & $24.2 \%$ & 115 & $84.5 \%$ \\
\hline 节日性购物 $^{1}$ & 58 & $42.6 \%$ & 118 & $86.7 \%$ \\
\hline KTV & 62 & $45.6 \%$ & 93 & $68.3 \%$ \\
\hline
\end{tabular}

在调查的 272 个人中, 男性 136 人参与率最高的为“电 视节目”, 参与率为 $75.7 \%$; 其次是“观看电影”, 参与率可 达 $50.7 \%$; “KTV”和“购物”活动男性参与率为 $45.6 \%$ 、 $42.6 \%$ ；参与率最低的为“广场舞”，仅为 $24.2 \%$ 。而女性 136 人参与率最高的为“电视节目”参与率为 $88.9 \%$; “购 物”“广场舞”“KTV”“电影”的参与率依次降低, 分别为 $86.7 \% 、 84.5 \% 、 68.3 \% 、 63.9 \%$ 。

可见, 从参与率上来看, 这些娱乐项目女性参与率均 高于男性。女性在大众娱乐文化的参与中占据重要地位。 随后, 我们从乐天影院、市政府广场、威高广场和幸福时 光 KTV 四个地点进行了为期一个月的实地调研, 得到数 据如下:

表 2 实地调研表

\begin{tabular}{|c|c|c|c|}
\hline 项目 & 男性占比 $(\%)$ & 女性占比 $(\%)$ & 总和 $(\%)$ \\
\hline 电影 & 44.79 & 55.21 & 100 \\
\hline 广场舞 & 11.95 & 88.05 & 100 \\
\hline 节日性购物 & 37.46 & 62.54 & 100 \\
\hline KTV & 40.21 & 59.79 & 100 \\
\hline
\end{tabular}

可见，在“电影”和“KTV”两种娱乐方式中，观看电影 的男性约占观看电影总人数的 $44.79 \%$, 观看电影的男性约 占观看电影总人数的 $55.21 \%$; 而去 KTV 的男性占唱 K 总 人数的 40.21 , 而女性参与者则占到了 $59.79 \%$ 。女性参与 要多于男性, 但总体来看, 男女人数差异并不是很大。而 在“购物”和“广场舞”两个方面, 男女参与度差距悬殊。在 购物人群中, 男性人数占购物总人数的 $37.46 \%$, 女性人数 占购物总人数的 $62.54 \%$, 女性人数约为男性的 2 倍; 在“广

1 这部分购物不包含日常生活用品的购物活动, 如买菜、购买针 线等。但包括在节假日逛街, 双 11 、双 12 淘宝等发展型消费。 
场舞”的参与方面, 男性只占到了参与总人数的 $11.95 \%$, 女性则占到了总人数的 $88.05 \%$, 约是男性的 8 倍。

从我们列举的几种具有代表性的大众娱乐文化的具体活 动的参与表现来看, 女性群体对大众娱乐文化的发展起到 十分重要的作用, 是大众娱乐文化的参与主体。在某些大 众娱乐文化项目, 如广场舞、购物节中, 女性甚至发挥了 主导作用。女性是大众娱乐文化的“主角”。

究其原因, 随着社会的发展进步, 社会中“男尊女卑” 的传统观念正逐步打破, “男女平等”的思想深入人心, 女 性在社会中也扮演了越来越多的重要角色。女性群体逐渐 摆脱了“第二性”的从属地位, 在某些领域发挥出了导向、 甚至是主导作用。同时, 女性群体在大众娱乐文化中地位 的确定, 与我国经济文化环境的发展以及大众娱乐文化的 特性有关。一方面, 随着社会、文化和经济的发展, 在“以 人为本” 的发展观指导下, 女性参加娱乐活动, 以达到健身 塑形、体验快乐、结交朋友的目的的人数大大增加, 丰富 的目的性也拓宽了大众娱乐文化的内容。通过大众娱乐活 动的途径来寻找突破口、消解自身压力和情绪也逐渐成为 大众女性的一种直接选择。而收入水平的提高、余暇时间 的增多, 又为女性参与娱乐活动提供了物资和时间保证。 因此, 在许多方面, 女性成为大众娱乐文化的主力军。另 一方面, 大众娱乐文化具有娱乐性、流行性、可消费、有 诱惑力等特点, 对女性有着直接的关联性与吸引力。大众 娱乐文化是人们在日常生活中寻求愉悦的方式的集合, 而 女性作为日常生活的主角, 自然成了大众娱乐文化的消费 主体。例如美容、教育、服饰、健身等等, 女性都是主要 的消费者。而以反映生活、表达情感为主的电视剧、电影 也往往以女性为主角, 吸引女性成为主要收视人群。另外,
女性是流行文化的主体。流行文化满足了女性对自身安全 感与优越性的心理需要与精神需求。因此, 女性更多地投 入到了对带有强烈流行性、诱惑力的大众娱乐文化的消费 过程之中。

大众娱乐文化作为一种与时俱进的群众文化, 女性群 体在其发展过程中起到了重要作用。因此, 我们要充分认 识、了解大众娱乐文化, 重视女性群体在大众娱乐文化发 展过程中发挥的主体作用和所占据的主导地位。在肯定娱 乐文化的必然性和合理性的前提下, 葆有清醒的价值评判 与审美导向, 从我国的具体国情出发, 引导不同群体和力 量, 使得大众娱乐文化健康发展。

\section{参考文献(Reference)}

[1] Tao Dongfeng. From Elitism to Non-Elitism-The Scanning of Three Decades' Literature in the New Era. Capital Normal University (Social Sciences) 2014 (01).

[2] Tao Dongfeng. Misunderstanding of Contemporary Chinese Popular Culture . Financial Expo 2014 (01).

[3] Song Xingming. Female Rhetoric of Mass Culture Propagation in Social Media Era. Huai Hua University. 2012 (10).

[4] Tan Yuchan, Zhao Lun. On the Rise of Mass Participatory Entertainment Culture and the Development of Social Democratic Consciousness. Huai Hai Wenhui. 2007 (06).

[5] Lai Daren. Template of Mass Entertainment Culture -- Cultural Interpretation of "Super Girl Phenomenon". Modern Communication (Journal of Communication University of China) 2006 (01). 